\title{
ANALYSIS OF SOME ASPECTS OF THE SURE AIRCRAFT SULFATE DATA
}

\author{
William T. ThOMPSON* and Robert D. BORNSTEIN \\ Department of Meteorology, San Jose State University, San Jose, CA 95192, U.S.A. and Systems \\ Applications, Inc., 101 Lucas Valley Road, San Rafael, CA 94903, U.S.A.
}

(First received 4 October 1982; in revised form 5 October 1984 and received for publication 18 March 1985)

\begin{abstract}
Aircraft data collected during the first five intensive and first episode periods of the Sulfate Regional Experiment (SURE) were analyzed through the lowest $3 \mathrm{~km}$ of the atmosphere to investigate possible long-range transport and transformation of sulfur pollutants. Results indicate average sulfate concentrations in the lowest $3 \mathrm{~km}$ over several stations generally higher in summer than winter, higher in afternoon than morning, and higher in the lower half of the layer than the upper half. Trajectory analyses for episode and non-episode periods in July 1978 show sulfur pollutants emitted in the Ohio River Valley possibly responsible for high sulfate concentrations in rural Pennsylvania and New York.
\end{abstract}

Key word index: Long range transport and transformation, sulfate, Sulfate Regional Experiment, sulfur dioxide, vertical sulfate climatology, trajectory analysis.

\section{INTRODUCTION}

Sulfate concentrations have been estimated as $0.8 \mu \mathrm{g} \mathrm{m}^{-3}$ over the North Atlantic (Prahm and Christensen, 1979), $1 \mu \mathrm{g} \mathrm{m}^{-3}$ over the United States (Altshuller, 1976), and $1.5 \mu \mathrm{g} \mathrm{m}^{-3}$ over Canada (Chung, 1978). However, urban sulfate values are as high as $83 \mu \mathrm{g} \mathrm{m}^{-3}$ under adverse meteorological conditions (Tong et al., 1976). Formation of sulfate aerosols by oxidation of atmospheric sulfur is temperature- and moisture-dependent and thus surface sulfate concentrations are higher in summer than winter, even though winter sources of atmospheric sulfur are stronger.

Afternoon sulfate values between 0.3 and $1.5 \mathrm{~km}$ above Philo, Ohio, as measured by the Sulfate Regional Experiment (SURE), were consistently higher than morning values during August 1977. According to Mueller et al. (1979), this result could be caused by "differences in day-night (insolationsensitive) formation rates." This also explains why almost no difference is seen between their corresponding afternoon and morning January values, i.e. low insolation period values. Little data exists on vertical differences in sulfate concentrations on the regional scale, but observations at Rockport, Indiana during one morning and afternoon in August 1977 showed lower concentrations in the layer from 1.5 to $3.0 \mathrm{~km}$ than in the layer from 0.3 to $1.5 \mathrm{~km}$ (Mueller et al., 1979).

Afternoon aircraft observations taken $100 \mathrm{~km}$ east of New York City (NYC) during January 1978 by

* Present affiliation: Naval Environmental Prediction Research Facility, Monterey, CA 93943, U.S.A. Author to whom correspondence should be addressed.
Michael et al. (1979) as part of the Multistate Air Pollution Power Production Study (MAP3S) showed sulfate values within the mixed layer from one to two orders of magnitude higher than those in the layers above. However, the fraction of sulfur in the form of sulfate was three to eight times larger above the mixed layer than within it.

Although sulfur dioxide levels in East Coast urban centers have generally decreased because of the change to low sulfur fuels and relocation of power plants to the Ohio River Valley, sulfate levels in these areas did not decrease accordingly (Altshuller, 1976). This 'sulfate anomaly' is believed to be due to long-range transport of sulfur dioxide accompanied by its simultaneous chemical transformation to sulfate. Longrange transport is believed to be enhanced by the tall stacks used with the new Ohio River Valley sources to reduce local sulfur dioxide concentrations.

Previous observational studies indicate long-range transport of sulfate and its precursors related to high local ambient sulfate concentrations, e.g. Wolff (1979) found 75 per cent of the sulfate in New York State (NYS) not produced within the state. Sulfur dioxide roses constructed by Zeeduk and Velds (1973) showed concentrations in the Netherlands dependent on wind direction. That study, and one by den Tonkelaar (1978) using a surface monitoring network, showed the industrial Ruhr Valley producing high sulfate concentrations in the Netherlands. Visual imagery from the SMS1 satellite was used by Lyons et al. (1978) and Parmenter (1977) to follow pollutant clouds from the midwest to the northeastern United States.

Analyses by Samson $(1978,1980 \mathrm{a})$ and Galvin et al. (1978) showed sulfate and ozone transport over long distances producing high concentrations in rural NYS. Similar analysis by Milan and Chung (1977) showed 
high sulfate concentrations in southern Quebec resulting from long-range transport from the south. In addition, the Diagnostic Atmospheric Cross-Section Experiment (DASCE-1) of MAP3S showed sulfate transport taking place on isentropic surfaces (MacCracken, 1979).

The SURE backwards trajectory model described by Hidy et al. (1976) used 2000 foot ( $\sim 610 \mathrm{~m}$ ) winds to construct 24-h long-range transport trajectories. Similar 72-h trajectories were constructed by Miller et al. (1978), Samson (1980a, b, c), and Gotaas (1982). The four level (surface to $1600 \mathrm{~m}$ ) numerical diagnostic trajectory model of Hefter and Taylor (1975) was used to construct similar long-range transport trajectories over the eastern U.S. by Lioy et al. (1980).

Preliminary results from SURE (Lavery et al., 1979) show two different synoptic patterns associated with long-range transport and high rural sulfate 'episode' concentrations. The first, a 'stagnation' situation, involves a slow moving anticyclone which collects primary pollutants from the industrial areas of the Ohio River Valley and transports them slowly eastward. The second involves 'channeling,' in which a duct is established between the Appalachian Mountains and a weak cold front oriented west-southwest to eastnortheast and travelling southeastward.

In the current study, sulfate and sulfur dioxide data collected by research aircraft as part of the SURE experiment are used to prepare preliminary concentration climatologies through the lowest $3 \mathrm{~km}$ of the atmosphere over the northeastern United States. Radiosonde data are used to construct long-range 850$\mathrm{mb}$ isobaric trajectories for one low sulfate concentration period and one sulfate episode period during July 1978.

\section{ANALYSIS}

Instrumented aircraft were flown during the first five SURE routine 'intensive' observational periods and one high concentration 'episode' period (designation by SURE investigators based on surface concentrations) during 1977 and 1978 (Table 1). A Beechcraft Queen Air was flown by Meteorology Research Inc. (MRI) and a Piper Navajo was flown by Research Triangle Institute (RTI). The aircraft measured particulate and gaseous pollutant concentrations, as well as temperature, dew point, turbulent intensity, sky cover and visibility.

Both planes were equipped with a Meloy 285 flame photometric sulfur dioxide device. In addition, 47-mm coated filters, manufactured by Brookhaven National Laboratory, were also used to measure sulfur dioxide starting in the RTI aircraft in January 1978 and the MRI aircraft in April 1978 The Navajo aircraft used the same filters for measuring respirable sulfur particulates, whereas the Beechcraft used Environmental Research and Technology instrumentation for this purpose. Details of instrumentation, as well as preliminary listings of unvalidated data, are in Keifer (1979).

During intensive periods, each aircraft collected data in the vicinity of the SURE stations listed in Table 1. During the episode period, the aircraft did not remain near a single station, but flew traverses between the two stations listed in the Table. All sites listed in Table 1 are located in Fig. 1.

On each sampling day during an intensive period, both morning "a.m." and afternoon "p.m." flights were flown by each aircraft. The early flight was near sunrise or midmorning, while the later flight was midafternoon or early to late evening. Each flight consisted of a vertical spiral after takeoff, a horizontal traverse to the flight midpoint, a second vertical spiral, a second horizontal traverse, and a final vertical spiral. A single filter was used for sulfate and sulfur dioxide in the lower halves of all three spirals (near surface to $1500 \mathrm{~m}$ ), and a different one for the upper halves of all three spirals (1500-3000 m). On days during the episode period, each plane flew from one airport to the other in the morning and then back in the afternoon. Filters were changed at the midpoint of each flight, yielding two observational values per flight.

To produce a 'vertical sulfate climatology' for the SURE

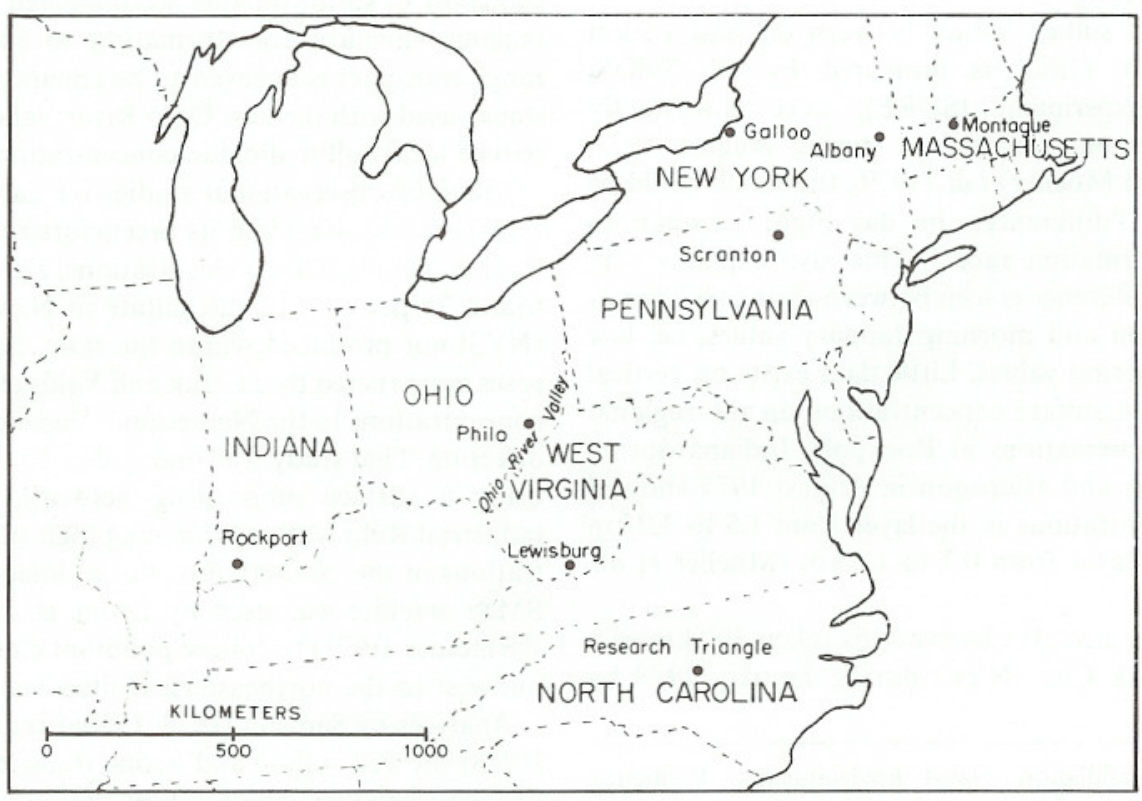

Fig. 1. Map of SURE region showing locations of observational sites. 
region, concentration data from both sites on each sampling day (Table 1) during a particular intensive period were used to compute average values of sulfate content in a unit-area column for the morning lower layer, morning upper layer, afternoon lower layer, and afternoon upper layer. Concentration values were multiplied by column depth to produce sulfate content values in $\mu \mathrm{g} \mathrm{m}^{-2}$. Since data were collected at Philo during four of the five intensive periods, the same averaging procedure was used to compute a separate climatology for this station. A similar procedure had been used by Mueller et al. (1979) for Philo data from August 1977 to January 1978 .

The maximum recorded sulfate value in the upper layer $\left(22.4 \mu \mathrm{g} \mathrm{m}^{-3}\right)$, from the morning of $16 \mathrm{July} 1978$, at Philo, appeared excessive when compared with other upper layer data. Thus, an average of morning observations taken immediately before and after this day $\left(1.6 \mu \mathrm{g} \mathrm{m}^{-3}\right)$ was used in its place. A similar procedure replaced a sulfur dioxide reading of $90.0 \mu \mathrm{g} \mathrm{m}^{-3}$ from the second half of the 20 July morning flight from Philo to Rockport with one of $35.0 \mu \mathrm{g} \mathrm{m}^{-3}$. It is possible that the first replaced value was due to a point source plume in the sounding. This also could be true for the second replaced value if a significant portion of the traverse was within a plume. Plume contamination is always a potential problem in regional scale problems. Use of the two questionable original data would result in strengthening conclusions reached below.

To investigate the possible role of long-range transport in producing high sulfate values observed during the episode period, backward trajectories ending at Albany, New York were constructed at $12-\mathrm{h}$ intervals. Rawinsonde winds from the $850 \mathrm{mb}$ level from the episode and intensive periods of July 1978 were used as input to the SURE trajectory model (Hidy et al., 1976) to construct 48- to 72-h isobaric trajectories.

\section{RESULTS}

\section{(a) Sulfate climatologies}

The climatology of total sulfate from near surface to $3 \mathrm{~km}$ at Philo (Fig. 2) shows summer maxima and winter minima during both a.m. and p.m. periods, as is also true for the lower layer data. However, this is not true for the upper layer data, as a.m. values during the second Summer are less than corresponding spring values and p.m. winter values are greater than corresponding second summer values. In addition, only in this last case are upper values greater than corresponding lower values. Finally, all p.m. values (i.e. total, upper and lower) are greater than corresponding a.m. values during all seasons.

The preliminary Philo results of Mueller et al. (1979) show seasonal and diurnal patterns similar to the above results, even though they only used some of the Summer 1977 and Winter 1978 data from the lower layer and no upper layer values. In particular, they found higher summer than winter values during both a.m. and p.m. periods and higher p.m. than a.m. values in summer, but approximately equal values in winter. Finally, their one day of data from Rockport showed smaller lower-level values during both time periods. The general decrease of sulfate with altitude was also supported by their 24-h-averaged surface sulfate values, which were about three to four times greater than average a.m. and p.m. lower layer readings.

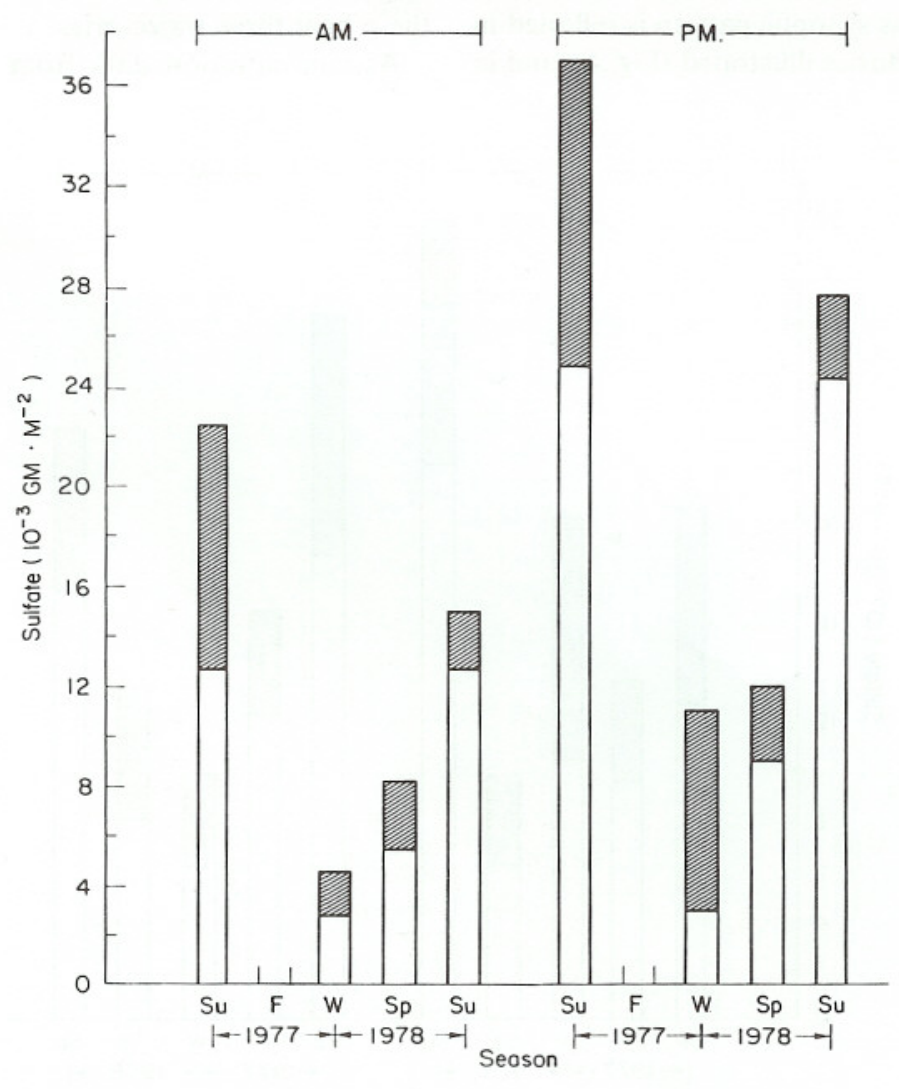

Fig. 2. Climatology of total sulfate in column of air to $3 \mathrm{~km}$ at Philo, Ohio, with shaded regions indicating values in upper half of layer. 
The 'regional' climatology (Fig. 3) has some features which are consistent with the Philo climatology, however, there are significant differences. For example, in all seasons a.m. and p.m. upper layer values are less than corresponding lower layer values for both Philo and the region. However, summer maxima and winter minima only appear in the total p.m. values, but not the total a.m. values. Finally, p.m. values are not consistently greater than a.m. values for either the total column or its upper and lower layers. Thus, Philo is not always representative of the entire Northeast.

\section{(b) Trajectory case studies}

All 12 trajectories computed during the 11-14 July 1978 non-episode period were only $48 \mathrm{~h}$ long because of the relatively high wind speeds during the period. In addition, only one (or possibly two) trajectories passed through high emissions areas around the Ohio River Valley (Figs $4 a-c)$. The four trajectories terminating from 1900 EST on the 11th to 0700 EST on the 13th originated in northern or central Ontario (Fig. 4a), far north of the Valley. These later trajectories reflect the presence of a trough at $850 \mathrm{mb}$.

The more zonal orientation of trajectories on the following two days (Fig. 4b) reflect entrance of a broad short-wave ridge at $850 \mathrm{mb}$. Although these trajectories are nearer to the Ohio River Valley, only the one terminating at $0700 \mathrm{EST}$ on the 15 th actually passed close to it.

Continuation of this synoptic pattern is reflected in the two earliest trajectories illustrated (Fig. 4c) and in the first third of the trajectory arriving at Albany at 1900 EST on the 16th. However, movement of a closed low at $850 \mathrm{mb}$ to the East Coast during early morning hours on the 15 th is reflected in the change to a meridional orientation in the latter two-thirds of this trajectory and in the almost closed loop of the following one.

Trajectories computed for the high sulfate 'episode' period during the third week of July 1978 (Figs 5a and b) were longer than those of the intensive period. They ranged from 48 to $72 \mathrm{~h}$ due to the generally lower wind speeds during this period, as compared with those during the intensive period. Four, and possibly five, of the eight trajectories constructed for this episode period passed through high emissions areas around the Ohio River Valley.

The earliest trajectory (Fig. 5a) reflects replacement of the ridge of the 18th by a trough on the 19th, as this trajectory and the second half of the next one (0700 EST on the 19th) did not pass through the heavy emissions area. The final two trajectories of Fig. 5(a), and the earliest one of Fig. 5(b) (i.e. arrival at 1900 EST on the 20th), did slowly pass over the heavy emissions area as the trough moved through. The next trajectory passed north of the emissions area, but that at 1900 EST on the 21st (Fig. 5b) again passed over it. The final trajectory, which passed north of the area, is quite similar to that $24 \mathrm{~h}$ earlier. The presence of a ridge which moved into the area on the 21 st is seen in these final three trajectories.

As concentration data from the intensive period

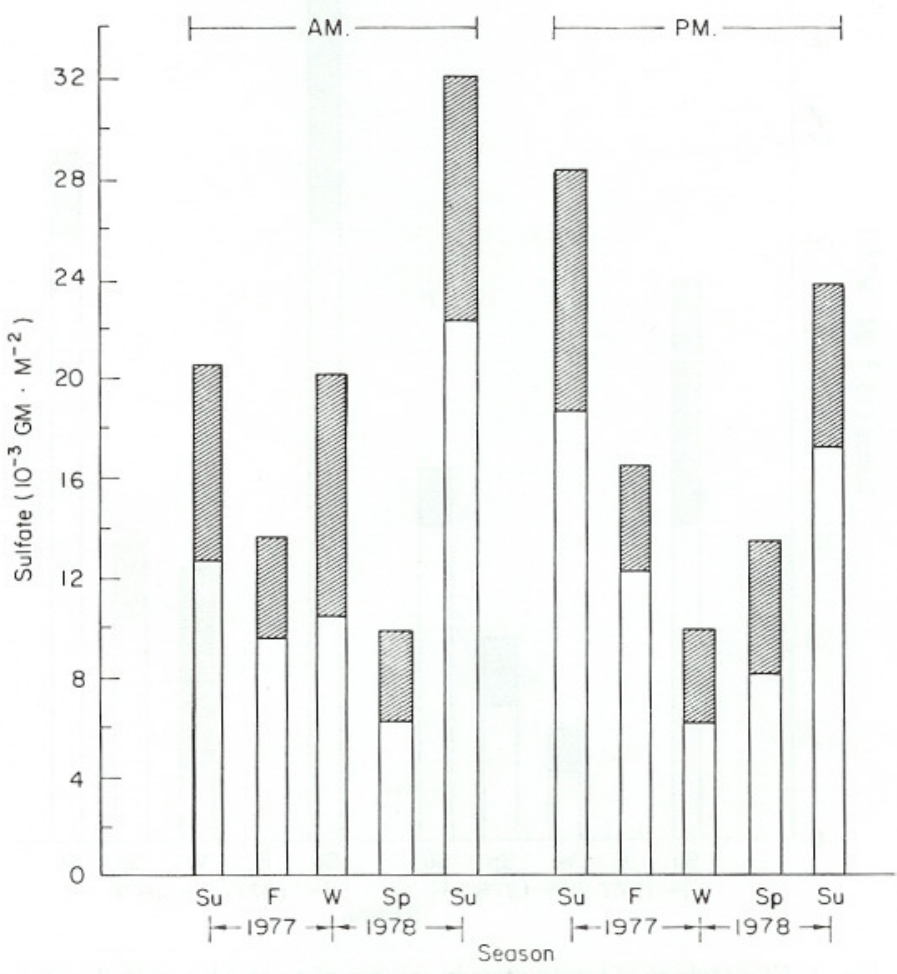

Fig. 3. Same as Fig. 3, but for entire SURE region. 
consisted of vertical spirals from the surface to $3 \mathrm{~km}$, and data from the episode period consisted of $300 \mathrm{~km}$ long horizontal traverses at elevations near $1 \mathrm{~km}$, it is difficult to compare the two data sets. However, data from the intensive period (12 to 16 July) in the lower layer (i.e. $0-1500 \mathrm{~km}$ ) can be compared with those from the episode period (19-21 July).

Results (Fig. 6) show average concentrations of both pollutants higher during the episode than during the intensive period, with sulfur dioxide levels showing the greater percentage increase. Thus, the general 'sulfate greater than sulfur dioxide' pattern of the intensive period reversed throughout the episode.

Two caveats should be kept in mind when viewing the above results. First, traverse data from the MRI aircraft were taken along paths from Scranton to Galloo on the 19th and 20th and from Scranton to Montague on the 21st (Table 1). Second, each morning and evening data point for a given day represents either the average of two traverses (for episode period) or one sounding each from two sites (for intensive period).

Average concentrations of both pollutants were higher at Philo than at Scranton during the intensive period (Table 2). This is expected given the trajectories illustrated in Figs. 4(a)-(c), as Scranton is only in- frequently downwind of the large sulfur dioxide sources around Philo. Average sulfur dioxide concentrations were also higher along Rockport to Philo traverses than along Galloo or Montague to Scranton traverses during the episode period (Table 2), when the trajectories of Figs 5(a) and (b) show Scranton frequently downwind of the large sulfur dioxide sources around Philo. However, sulfate concentrations were higher along Scranton traverses during this period, thus providing evidence for sulfur dioxide to sulfate transformation in conjunction with the longrange transport implied by the trajectory analysis.

The position of a surface cold front during the 'episode' was similar to that which produced longrange transport of the channeling type detailed by Lavery et al. (1979). In addition, high temperatures and humidities, as well as low wind speeds at the surface and $850 \mathrm{mb}$ during the episode, favored a more rapid and complete conversion of sulfur dioxide to sulfate during movement to Scranton. Additional evidence for transformation is found in the higher $R$-values (ratio of sulfur content of sulfate to sulfur content of sulfur dioxide plus sulfate) along Scranton traverses than along Philo traverses during the episode. This is reversed from conditions during the intensive period (Table 2).

Table 1. Aircraft data collection protocol during SURE intensive periods and episode period (shown by $\ddagger$ ) collected by aircraft

\begin{tabular}{|c|c|c|}
\hline Dates & RTI Aircraft & $\begin{array}{l}\text { Sites } \\
\text { MRI Aircraft }\end{array}$ \\
\hline $\begin{array}{l}1977 \\
1,3,5,7,9,11 \text { August }\end{array}$ & Philo & Rockport \\
\hline $19,21,23,25,29,31$ November & Scranton & Rockport \\
\hline $\begin{array}{l}1978 \\
22,24,27-31 \text { January }\end{array}$ & Lewisburg & Philo \\
\hline $12,14-16,18,20-22,24$ April & Research Triangle & Philo \\
\hline $12,14,16$ July & Philo & Scranton \\
\hline$\ddagger 19-21$ July & Philo to Rockport & $\begin{array}{l}\text { Galloo to Scranton } \\
\text { (on } 19 \text { and } 20 \text { July) } \\
\quad \text { and } \\
\text { Galloo to Montague } \\
\text { (on July } 21 \text { ) }\end{array}$ \\
\hline
\end{tabular}

Table 2. Concentration data for July 1978 intensive and episode periods, where $R$ is the ratio of sulfur content of sulfate to total sulfur content (sulfur dioxide and sulfate)

\begin{tabular}{|c|c|c|c|c|c|}
\hline \multirow[b]{2}{*}{ Sites } & \multicolumn{2}{|c|}{$\begin{array}{c}\text { Sulfate } \\
\left(\mu \mathrm{g} \mathrm{m}^{-3}\right)\end{array}$} & \multicolumn{2}{|c|}{$\begin{array}{c}\text { Sulfur dioxide } \\
\left(\mu \mathrm{g} \mathrm{m}^{-3}\right)\end{array}$} & \multirow{2}{*}{$\begin{array}{c}R \\
\text { (Per cent })\end{array}$} \\
\hline & Range & Average & Range & Average & \\
\hline \multicolumn{6}{|l|}{ Intensive (soundings)* } \\
\hline Philo & $5.02-27.8$ & 15.9 & $1.6-32.3$ & 16.3 & 36.9 \\
\hline Scranton & $1.0-13.0$ & 7.0 & $6.6-15.8$ & 10.0 & 29.6 \\
\hline \multicolumn{6}{|l|}{ Episode (traverses) $\dagger$} \\
\hline Rockport to Philo & $11.4-45.9$ & 26.8 & $11.4-55.5$ & 38.6 & 29.4 \\
\hline $\begin{array}{l}\text { Galloo to Montague } \\
\text { or Scranton }\end{array}$ & $10.1-46.8$ & 31.9 & $11.6-56.7$ & 28.7 & 40.0 \\
\hline
\end{tabular}

* Averages of two soundings each on three days.

$\dagger$ Averages of two segments each for two traverses each on three days. 

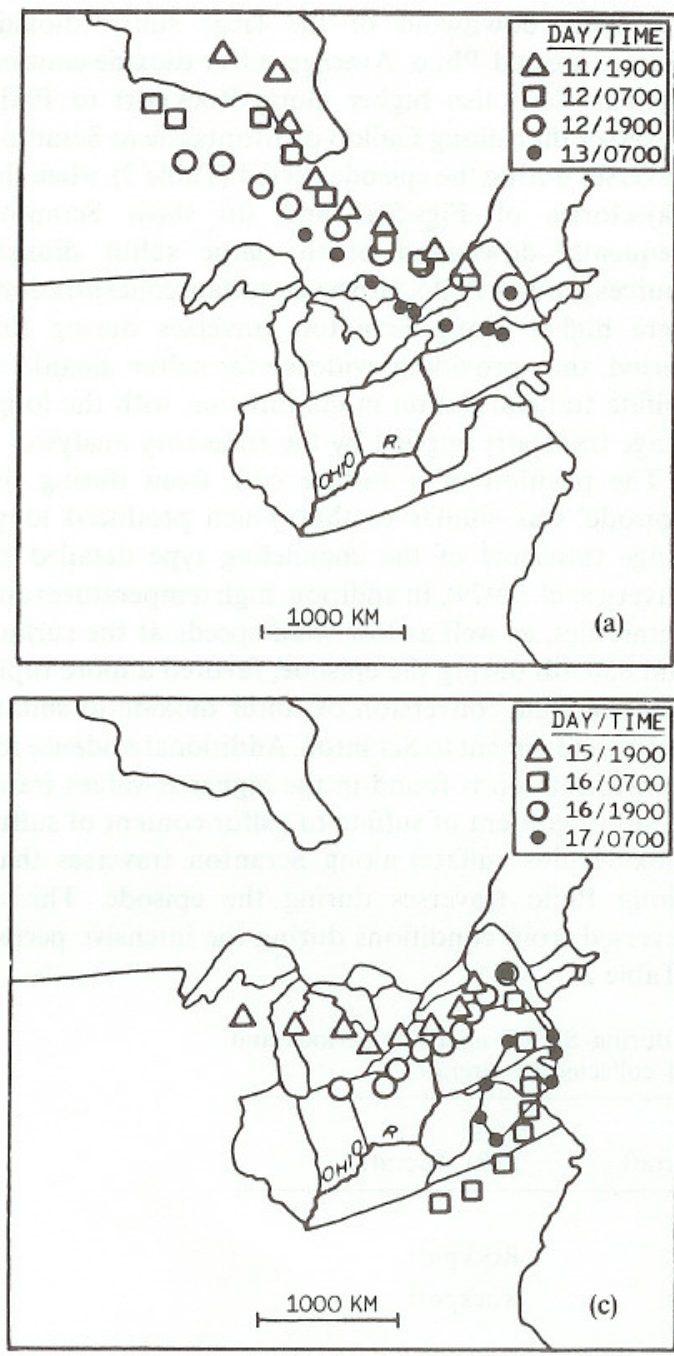

Fig. 4.(a)-(c) Trajectories ending at Albany, New York, during July 1978 intensive period.

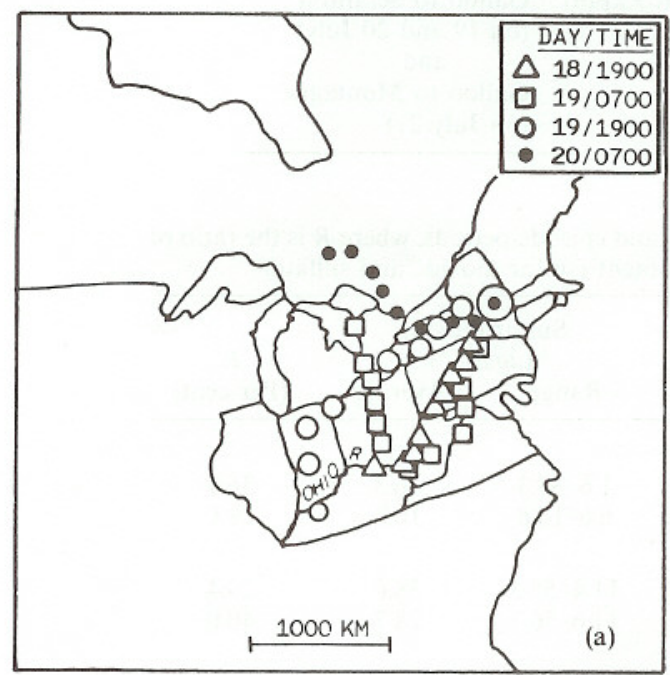

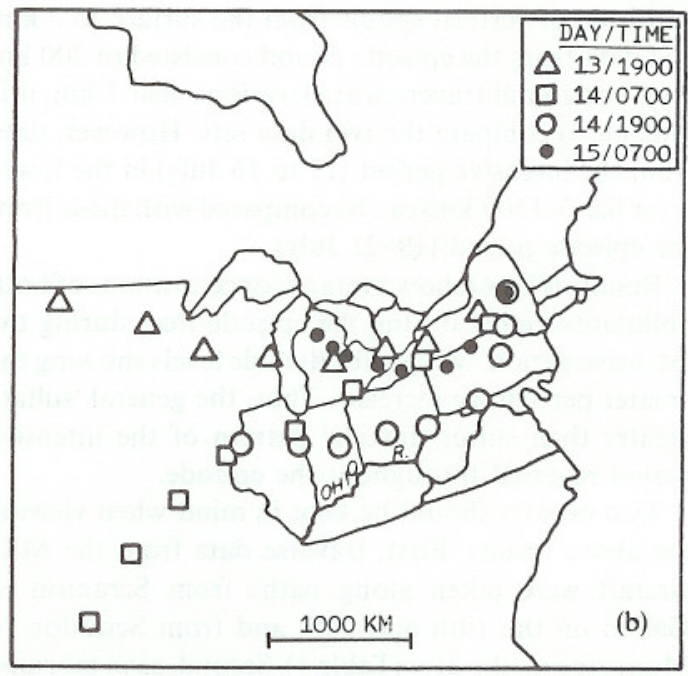

\section{CONCLUSIONS}

Sulfur dioxide and sulfate concentration data collected by research aircraft in the lowest $3 \mathrm{~km}$ of the atmosphere over the northeastern Unites States during five seasons from Summer 1977 to Summer 1978 as part of the SURE experiment have been analyzed. Rawinsonde data from July 1978 were used to construct $850 \mathrm{mb}$ isobaric long range trajectories during a low sulfate concentration intensive period and a high sulfate concentration episode.

Results showed seasonally averaged sulfate values in the column from near surface to $3 \mathrm{~km}$ at Philo to be greatest in summer and lowest in winter during both morning and afternoon hours. This pattern was also true in the lower half of the layer, but not the upper half. All but one of the 10 seasonal averages (five morning and five evening) from the lower layer were greater than

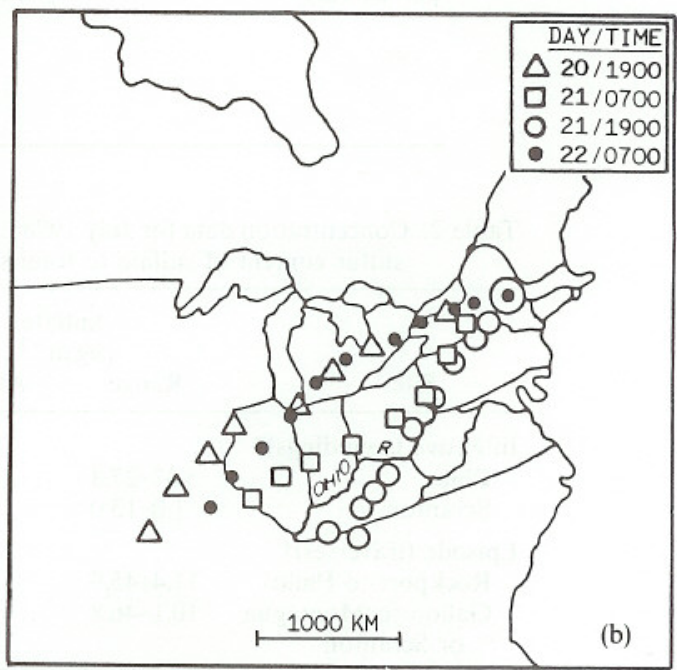

Fig. 5.(a) and (b). Same as Fig. 4, but for July 1978 episode period. 
corresponding upper layer values. All afternoon values (i.e. total, upper and lower) were greater than corresponding morning values during all seasons. A climatology for the region showed similar results, except that summer maxima and winter minima did not appear in morning data for the total column, and evening values were not consistently greater than morning values for either the total column or its upper and lower halves.

Only one (or possibly two) of the computed 12 trajectories passing over Albany during the low concentration intensive period of July 1978 first passed over the high emissions area around the Ohio River Valley. However, four (or possibly five) of the eight trajectories passing over Albany during the high concentration episode period did pass over that area.

Daily averaged morning and afternoon concentrations of both sulfur dioxide and sulfate during July 1978 were generally higher during the episode than during the intensive period, with sulfur dioxide levels showing the greater percentage increase. Average concentrations of both pollutants were higher at Philo than Scranton during the intensive period, as expected from the distribution of sulfur dioxide sources and the trajectory analysis.

Average $\mathrm{SO}_{2}$ concentrations were also higher at Philo than Scranton during the episode, when trajectory analysis showed Scranton frequently downwind of the large sulfur dioxide sources near Philo. However, sulfate concentrations were higher near Scranton than Philo during this period, providing evidence for sulfur dioxide to sulfate transformation in conjunction with the long-range transport implied by the trajectory analysis. The low wind speed, high temperatures, and high humidities at the surface and $850 \mathrm{mb}$ during the episode favored more rapid and complete conversion of sulfur dioxide to sulfate during

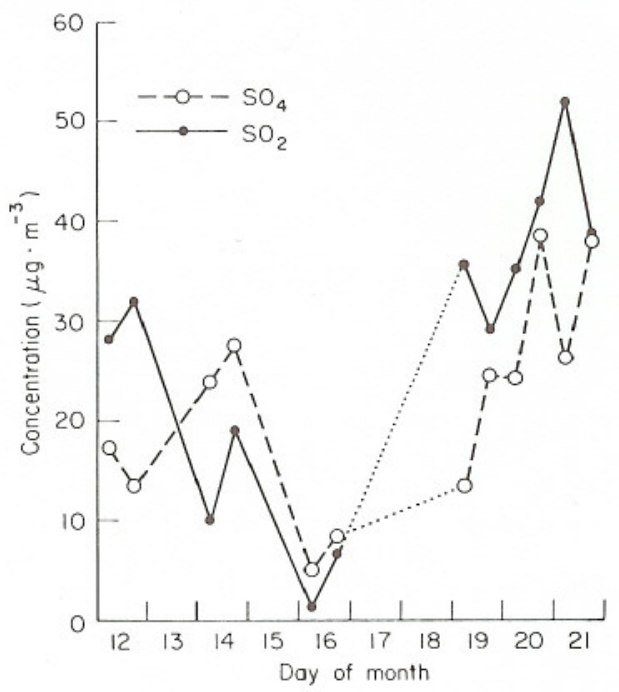

Fig. 6. Time variation of area-averaged sulfate and sulfur dioxide concentrations. movement to the Scranton area. Additional evidence for transformation were the higher ratios of sulfur content of sulfate to sulfur content of sulfur dioxide plus sulfate at Scranton than Philo during the episode, the reverse of that during the intensive period.

The current transport and transformation results are in variance with those of Samson (1980a), who found little correlation between downwind ambient sulfate concentrations and upwind sulfur dioxide emissions. He did, however, find a correlation between upstream stagnation and high downwind sulfate concentration. However, results from Lioy et al. (1980) and Tanner and Leaderer (1982) do agree with those of the present study with respect to parcel trajectory and high sulfate concentrations.

Future analyses of this type should utilize concurrent aircraft data collected by multiple aircraft, while future field programs should seek more detailed vertical and temporal resolutions of sulfate concentration. In addition, soundings and traverses for the same and different collection periods should be more comparable.

Acknowledgements - This research was carried out as part of a grant to Systems Applications, Inc from the EPA. The authors would like to thank Mrs. Cindy Le Fevre for typing the final manuscript.

\section{REFERENCES}

Altshuller A. P. (1976) Regional transport and transformation of sulfur dioxide to sulfates in the U.S. J. Air Pollut. Control Ass. 24, 318-324.

Chung Y.S. (1978) The distribution of atmospheric sulfates in Canada and its relationship to long range transport of air pollutants. Atmospheric Environment 12, 1471-1480.

den Tonkelar J. F. (1978) Long-range and inter-regional transport of sulfur dioxide towards the Netherlands during extremely unfavorable meteorological conditions. Preprint Volume WMO Symposium on Boundary Layer Physics Applied to Specific Problems of Air Pollution, World Meteorological Organization, 19-23 June 1978, Norrkoping, Sweden, pp. 393-399.

Galvin P. J., Samson P. J., Coffey P. E. and Romano D. (1978) Transport of sulfate to New York State. Envir. Sci.Technol. $12,580-589$.

Gotaas Y. (1982) Vertical distribution of sulphur in the atmosphere in a case of long-range transport and the rate of transformation to sulfate. Atmospheric Environment 16, 1043-1046.

Hefter J. L. and Taylor A. D. (1975) A regional-continental scale, transport, diffusion and deposition model. NOAA Tech. Memo., ERL ARL-50, U.S. Dept. of Commerce, Silver Springs, MD.

Hidy G. M., Tong E. Y. and Meuller P. K. (1976) Design of the sulfate regional experiment (SURE). Final report of research project 485, Vol. I-IV. Environmental Research and Technology, Concord, MA.

Kalthoff D. R. (1976) On sulfur dioxide removal and formation processes in the atmosphere. Preprint Volume Seventh NATO International Technical Meeting on Air Pollution Modeling and its Applications, Airlie, VA, pp. $1-14$.

Kaul U. K., Killus J. P., Wojcik M. A., Thompson W. T., Bornstein R. D., Seinfeld J. H. and Liu M. K. (1979) 
Development and evaluation of a mesoscale photochemical air quality simulation model. SAI Report No. E179-160 to U.S. EPA.

Keifer W. S. (1979) Aircraft measurements of pollutant and meteorological parameters in the SURE Network. Report submitted to EPRI for contracts RP 362-3, 36209, 5 Volumes.

Lavery T. F., Hidy G. M., Baskett R. L. and Thrasher J. (1979) Occurrence of long range transport of sulfur dioxides in the northeastern United States. Preprint Volume Fourth Symposium on Turbulence, Diffusion and Air Pollution. American Meteorological Society, 15-18 January 1979, Reno NV.

Lioy R. J., Samson P. J., Tanner R. L., Leaderer B. P., Minnich T. and Lyons W. (1980) The distribution and transport of sulfate "species" in the New York metropolitan area during the 1977 summer aerosol study. Atmospheric Environment 14, 1391-1408.

Lyons W. A., Dooley J. C. and Whitey K. T. (1978) Satellite detection of long range pollution transport and sulfate aerosol hazes. Atmospheric Environment 12, 621-631.

MacCracken M. C. (1979) The multi-state atmospheric power production study. Progress Report for FY 1977 and FY 1978, Lawrence Livermore Laboratory, Livermore, CA.

Millan M. M. and Chung Y. S. (1977) Detection of a plume at $400 \mathrm{~km}$ from the source. Atmospheric Environment 11, 939-949.

Michael P., Brown R. M. and Garber R. W. (1979) Comparison of particulate and gaseous material within and above the mixed layer. Preprint Volume Fourth Symposium on Turbulence, Diffusion and Air Pollution., 15-18 January 1979, Reno, NV, American Meteorological Society.

Miller J. M., Galloway J. N. and Likens G. E. (1978) Origin of air masses producing acid precipitation at Ithaca, New York-a preliminary report. Geophys. Res. Lett. 5, $757-760$.

Mueller P. K., Hidy G. M., Lavery T. F., Warren K. and
Baskett R. L. (1979) Some early results from the sulfate regional experiment (SURE). Preprint Volume Fourth Symposium on Turbulence, Diffusion and Air Pollution, American Meteorological Society, Reno, NV, pp. 322-329.

Parmenter F. C. (1977) Monitoring air quality from satellites. Mon. Weath. Rev. 105, 789-792.

Prahm L. P. and Christensen O. (1979) Long range transmission of pollutants simulated by a two-dimensional pseudospectral dispersion model. J. appl. Met. 16, 896-910.

Samson P. J. (1978) Ensemble trajectory analysis of summertime sulfate concentration in New York State. Atmospheric Environment 12, 1889-1893.

Samson P. J. (1980a) Trajectory analysis of summertime sulfate concentration in the northeast U.S. J. appl. Met. 19, 1382-1394.

Samson P. J. (1980b) Diagnostic modeling of summertime sulfate concentrations in the northeastern U.S. Second Joint AMS/APCA Conf. on Application of Air Pollution Meteor., New Orleans, LA, 28 March 1980.

Samson P. J. (1980c) An objective technique for determining the upstream $\mathrm{SO}_{2}$ emissions burden for long-range transport studies of atmospheric sulfate. 73rd Annual Meeting of the Air Pollution Control Association, Montreal, Quebec, 22-27 June 1980.

Tanner R. L. and Leaderer B. P. (1982) Seasonal variations in the composition of ambient sulfur-containing aerosols in the New York area. Atmospheric Environment 16, 569-580.

Tong E. Y., Hidy G. M., Lavery T. F. and Berland F. (1976) Regional and local aspects of atmospheric sulfates in the northeast quadrant of the United States. Preprint Volume Third Symposium on Turbulence, Diffusion and Air Quality, American Meteorological Society, 19-22 October 1976, Raleigh, NC.

Wolff G. T. (1979) The question of sulfates: a conference summary. J. Air Pollut. Control Ass. 29, 26-27.

Zeeduk H. and Velds C. A. (1973) The transport of sulfur dioxide over a long distance. Atmospheric Environment 7, 849-862. 